\title{
A Proposed Solution for Crime Reporting and Crime Updates on Maps in Android Mobile Application
}

\author{
Syed Mujtaba Raza \\ MSc. (IT). Student \\ Research and Innovation Management Center \\ SEGi University, \\ Kota Damansara, Malaysia
}

\author{
Leelavathi Rajamanickam, PhD \\ Senior Lecturer \\ School of Information Technology \\ SEGi University, \\ Kota Damansara, Malaysia
}

\begin{abstract}
The purpose of this research paper is to propose and develop an android mobile application for the general public awareness of the crime situation of their area and to provide them crime locations on the map. This application will also help general public to report a crime to law enforcement agency. This android mobile application will help public to see the locations on map which will help them to track the current situation of their surroundings. Some part of this android mobile applications is being developed in SEGi University with sample databases. In this research we will suggest some methods for future recommendations that how can law enforcement agencies avoid fake reports which are reported from mobile?
\end{abstract}

\section{Keywords}

General Public, Law enforcement agencies, Android mobile applications, Crime Reports, Crime Locations, Maps, PHP, JSON.

\section{INTRODUCTION}

Nowadays public wants themselves to be aware of security alerts in their surrounding areas. The security is very important part of everyone's life.

The role of police in society is very important for that purpose. Police is a government institution and responsible for the security of the lives and wealth of the public of the country.

Every time when police arrests criminals or gets crime reports they update those records in their database. Most of the times public of that area, where arrest is taken or crime is being reported, do not know that what is happening in their surroundings. That is the reason that most of them do not take initial security steps in their houses. However most of the crimes happen due to lake of security alerts and lake of awareness of the incidents in their neighborhoods. If public will get alerts and report crime timely then they can take some actions on the security of their lives and houses to make crimes difficult or stop [1].

A few countries are using such mobile applications to send alerts to the people of the communities for their safety purposes.

The users of those applications are appreciating these applications. These applications are creating an important role in the safety of the society.

Most of the mobile users are using smart phones to use health guide, news alerts and many more applications in daily life routine. Therefore a mobile application can be developed to show locations of crimes and to report a crimes. The application that will be developed can be used by the people of the specific area of which the database of police will be connected to application.

\section{PROBLEM STATEMENT}

Public need awareness of their neighborhoods. Everyone cares for the lives of children and their beloved ones so they should be aware of the current situations in the area. This research aims towards common people or public to help them in their lives by notifying them the current situation of their neighborhoods.

General Public and law enforcement agencies may use these kind of applications in many ways to keep the community aware of the current situations and to help them to live together by communicating and sharing information with each other.

- What are the locations of crimes in the surroundings?

- How to report the crime with evidence to law enforcement agencies?

\section{Research Methodology}

The main stakeholder who will use this android mobile application directly and that is general public. The general public will use this android mobile application to get the alerts and news of the crimes in their surrounding areas and also use this application to report the crimes. These crimes will be shown to them through a map.

\subsection{Tools and Techniques}

\subsubsection{Eclipse}

Eclipse is a good development tool for programming. This software is also used for the android programming. This software is available for royalty-free. In November 2001, Industry leaders Borland, IBM, MERANT, QNX software systems, Rationale Software, Red Hat, SuSE, TogetherSoft, and Webgain formed and initial Board of Stewards of this eclipse project as eclipse.org. In January 2014, IBM created an Eclipse Foundation which can work independently as a non-profit corporation $[3,8]$.

Eclipse software is user friendly. This software allows android development by installing the plugins of android. These plugins help developers to develop android application in user friendly environment. This allows to drag and drop user interface elements which is time saving for back end developers. 


\subsubsection{Java 1.8}

Java is a programming language which is an essential part of android operation system. Application that are developed for android have Java as primarily language. James Gosling designed Java at Sun Microsystems and released in 1995. It was promised that "Write Once, Run Anywhere. There were five main and primary purposes behind the development of Java as mentioned below:
i. It should be "simple, object oriented and familiar".
ii. It should be "robust and secure".
iii. It should be "architecture-neutral and portable".
iv. It should execute with "high performance".
v. It should be "interpreted, threaded and dynamic" $[4,10$, and 26].

\subsubsection{Android (Version 2.2,Froyo to Version 5.0,Lollipop)}

Android is a mobile operating system which is written in $\mathrm{C}$ (core), C++ and Java (UI). Android Inc. was founded in October 2003 by Andy Rubin, Rich Miner, Nick Sears and Chris White. This operating system will help to create this android mobile application [24].

Android is most dominant in the market of mobiles with shares of $78.0 \%$ in the year 2014 and is expecting to remain with same rates in the 2015 [29].

\subsubsection{Android Software Development Kit (SDK)}

Android applications are developed in Java programming language for which Android SDK is used. Android SDK comprises on complete set of development tools. These development tools consists of debugger, libraries, emulator, documentation, sample code and tutorials [5, 11]

\subsubsection{Android Development Tool (ADT)}

We are using IDE Eclipse to develop this android mobile application for which ADT plugin is required. This plugin provides us many features which are very helpful in the android mobile applications development. This provides an easy access to UI design to develop prototype, design and user interface rapidly.

In addition to this, ADT provides Extensible Mark-up Language (XML) which helps developers to create and edit Android manifest, resources, menus and layouts in two different modes that are form-based and graphical.

ADT not only provides normal coding mode but also provides to jump to different resources such as strings or layout files [9].

\subsubsection{MySOL Database}

MySQL Database is a free open source database software which will help us to save our data and to retrieve data through android mobile application. MySQL is the second most widely used database in the world. MySQL was named after the daughter of co-founder Michael Widenius, My. The SQL stands for Structured Query Language.
MySQL was initially released on 23 May, 1995 by MySQL AB. Now this is owned by Oracle Corporation. TYPO3, MODx, Joomla, WordPress, phpBB, MyBB, Druphal are some of the famous software which are using MySQL.Google, Facebook, Twitter, Flickr and YouTube are some of those famous and large scale websites which are using MySQL [6, 12, and 13].

\subsubsection{MySQL Workbench}

MySQL workbench is a MySQL database tool which will provide us to interact with our database in easy way. The official integrated environment for MySQL is MySQL Workbench which was developed by MySQL AB. MySQL Workbench allows users to graphically administer MySQL database. It also allows users to manage database design and modelling, SQL development and database management.

MySQL Workbench is available in two different editions, the regular free and open source Community Edition and the proprietary Standard Edition [6, 7 and 13].

\subsubsection{PHP}

PHP is a server side programming language which was designed by Rasmus Lerdof in 1994 the reference implementation is now produced by The PHP Group. As of January 2013, more than 240 million websites and 2.1 million web-servers installed PHP.

This language will help to get the information from MySQL database to android mobile application and also help to insert data to MySQL database from android mobile application [14, 33].

\subsubsection{JavaScript Object Notation (JSON)}

JavaScript Object Notation (JSON) transmits data objects in the form of attribute-value pair which is human readable text. JSON is an open standard format. JSON is derived from JavaScript but JSON is a language independent data format. Many programing languages supports for coding to parse and generate JSON data. The JSON format was originally designed by Dougals Crockford.

JSON is a scripting programming language. This language will help to send and receive data from PHP to android mobile application and vice versa $[15,34]$.

\subsubsection{0. ХАМPP}

XAMPP was introduced by Apache Friends on 22 May, 2002 This is an open source cross-platform web-server solution stack package. This mainly comprises Apache HTTP server, MySQL database and interpreters for the scripts written in PERL and PHP programming languages. This was designed with intention to provide test environment on personal computers without access to internet so that website designers and programmers can use it to test their websites on their own computers. 


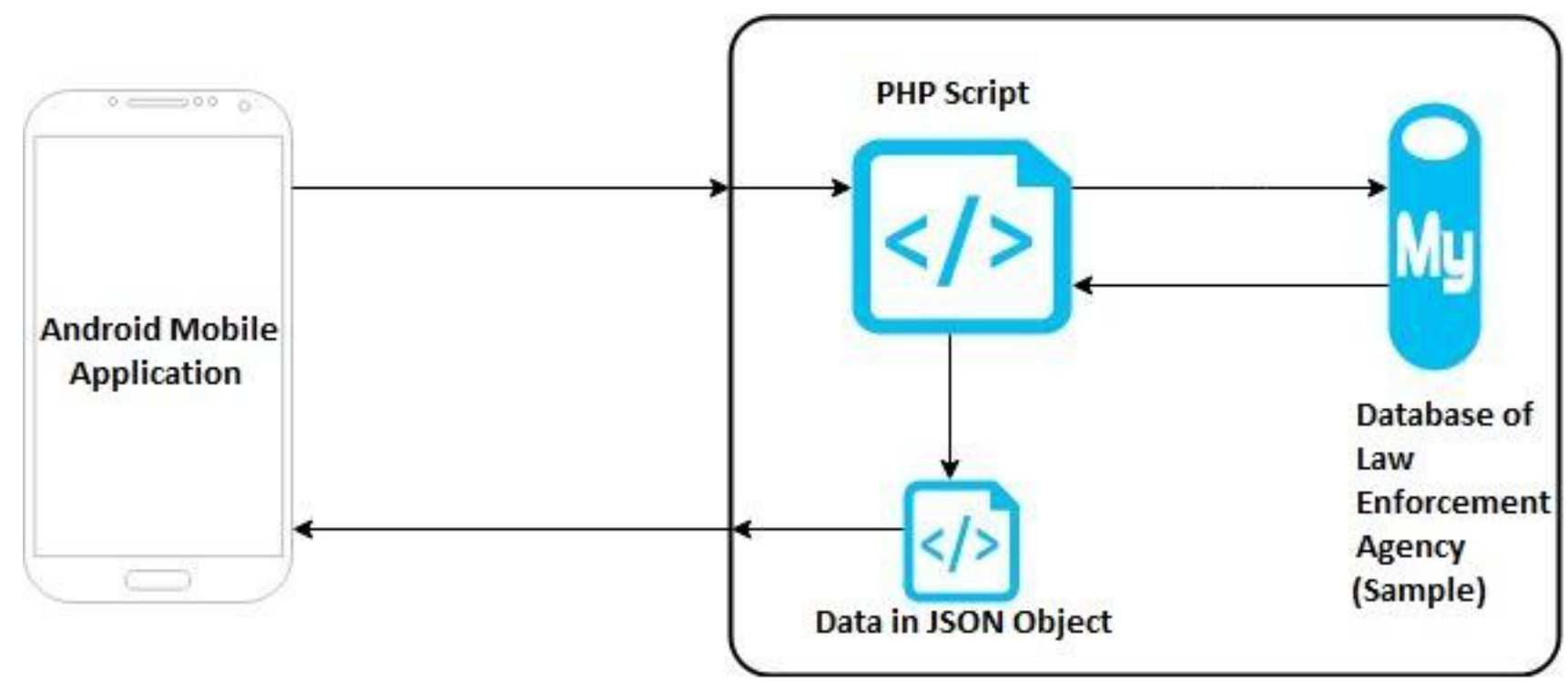

Fig 1. Workflow diagram of android mobile application system

XAMPP also allows to create and manipulate MySQL and SQLite databases.

XAMPP is PHP development environment. This will help to run PHP, Apache tomcat server and MySQL [16, 35].

\subsubsection{Google Maps Android API}

Google maps android API is used to deploy maps in this android mobile application [17, 36].

\subsection{Workflow}

The android application will be connected to the database of law enforcement agency (sample). PHP script will get information from database. This script will create a JSON object of the data which is collected from database. That JSON object will be sent to android application. This object will contain the crime location information which will be shown on map.

When general public have to report a crime then they will open application to attach or take photo and send that photo with crime category to the database. The information of the user will be verified at the time of signup so that if the report is fake then the law enforcement agencies can take action against the reporter.

\section{FUTURE RECOMMENDATION}

For future work this application can be integrated with the traffic police database to tell the locations of traffic blockages, construction in progress etc. This application can also be further expand to convert into send live videos from android application to desktop server of law enforcement agencies to view the current situation of strike, fight etc. The facial expression algorithms can be used to find criminals. The photos and videos which will be sent by people to check whether video or photo is edited or not some steps can be taken in the application to avoid fake evidences for example the images can be embedded with special identity so that if someone try to send edited image that image will not be accepted and law enforcement agency can take action against the reporter [25].

The algorithms can be used to delete the number of data which is not useable to free the space of the database. If some law enforcement agency want to use this application a request option can be shown so that after confirmation of that requests their database can be attached to this application. When a number of agencies will be attached the scope to control the crime will increase.

\section{ACKNOWLEDGMENT}

First of all, I am very grateful to Allah, most merciful and most gracious, who blessed me the strength and knowledge to complete this research paper.

I would like to thanks to my supervisor, Dr. Leelavathi Rajamanikan. I appreciates her useful information to complete this thesis. I would also like to thanks to Dr. Shaheen Mansori, Dr. Kousay, Dr. Lai, Dr. Vinod, Dr. Yap and Dr. Norriza who helped me to write the thesis and taught me the methods of conducting research. I am also thankful to head of department Dr. Mahadevan for his support to provide us great environment to conduct research. I would like to thanks to staff of our SEGi University, IGS and RIMC department and Faculty of Information Technology.

I am very thankful to my family to support me throughout my life with their love and prayers. I would also like to thank to my friends who encouraged me to complete this paper.

Then I would like to thanks to the researchers of the papers and developers whose references I used. These references helped me a lot to complete this paper.

At the end I would like to dedicate this research paper to the people who are victims of terror in all over the world.

\section{REFERENCES}

[1] Causes of Crime - Explaining Crime, Physical Abnormalities, Psychological Disorders, Social and Economic Factors, Broken Windows, Income and Education.

[2] My Maps https://www.google.com/maps/d/

[3] Eclipse IDE https://eclipse.org/org

[4] Java http://java.com 
[5] Android Software Development Kit http://developer.android.com/sdk/index.html

[6] MySQL Database http://www.mysql.com/

[7] MySQL http://www.mysql.com/products/workbench/

[8] About the Eclipse Foundation : History of eclipse https://www.eclipse.org/org/ Date of extraction: March 7, 2015

[9] Android Development Tool https://developer.android.com/tools/help/adt.html Date of extraction: March 7, 2015

[10] Android Operating System : Applications http://en.wikipedia.org/wiki/Android_\%28operating_syst em\%29 Date of extraction: March 10, 2015

[11] Android Software Development: Android SDK http://en.wikipedia.org/wiki/Android_software_develop ment Date of extraction: March 10, 2015

[12] About MySQL http://www.mysql.com/about/ Date of extraction: March 10, 2015

[13] MySQL http://en.wikipedia.org/wiki/MySQL Date of extraction: March 10, 2015

[14] PHP http://php.net/ Date of extraction: April 8, 2015

[15] JSON http://json.org/ Date of extraction: April 8, 2015

[16] XAMPP https://www.apachefriends.org/index.html Date of extraction: April 8, 2015

[17] Google Maps Android API https://developers.google.com/maps/documentation/andr oid/start\#getting_the_google_maps_android_api_v2 Date of extraction: April 8, 2015

[18] Amit Kushwaha, Vineet Kushwaha. March 2011. Location Based Services using Android Mobile Operating System. Date of extraction: April 8, 2015

[19] Xianhua Shu, Zhenjun Du, Rong Chen. Research on Mobile Location Service Design Based on Android. Date of extraction: April 8, 2015

[20] Prof. Seema Vanjire, Unmesh Kanchan, Ganesh Shitole, Pradhyesh Patil. January 2014. Location Based Services on Smart Phone through the Android Application. Date of extraction: April 8, 2015

[21] Manav Singhal, Anupam Shukla. January 2012. Implementation of Location based Services in Android using GPS and Web Services. Date of extraction: April 8,2015
[22] Reto Meier. May 2012. Professional Android 4 Application Development. Indianapolis: WROX.

[23] Android https://www.android.com/ Date of extraction: June 6, 2015

[24] Dr. A. Bharati, R. Shilpa. August, 2014. A survey on crime data analysis data mining using clustering techniques. Date of extraction: 17 June, 2015.

[25] Rory Cellan-Jones. (2015, June 8) EyeWitness app lets smartphones report war crimes. http://www.bbc.com/news/technology-33029464 Date of extraction: June 12, 2015

[26] Revatthy Krishnamurthy, J. Sateesh Kumar. December, 2012. Survey of data mining techniques on crime data analysis. Date of extraction: 18 June, 2015.

[27] D.E. Brown, "The regional crime analysis program (RECAP): A Frame work for mining data to catch criminals," in Proceedings of the IEEE International Conference on Systems, Man, and Cybernetics, Vol. 3 pp. 2848-2853, 1998

[28] Java (Programming Language) https://en.wikipedia.org/wiki/Java_(programming_langua ge) Date of extraction: 18 June, 2015

[29] Smart Phones OS Market Share, Q1 2015 http://www.idc.com/prodserv/smartphone-os-marketshare.jsp Date of extraction: June 19, 2015.

[30] Aijaz Ahmad Sheikh, Prince Tehseen Ganai, Nisar Ahmad Malik, Khursheed Ahmad Dar. SeptemberOctober 2013. Smartphone: Android Vs IOS http://www.thesij.com/papers/CSEA/2013/SeptemberOctober/CSEA-0104600401.pdf Date of extraction: June 19,2015

[31] Android - Architecture http://www.tutorialspoint.com/ android/android_architecture.htm Date of extraction: June 19, 2015

[32] Draw www.draw.io

[33] PHP https://en.wikipedia.org/?title=PHP Date of extraction: 22 June, 2015

[34] JSON https://en.wikipedia.org/wiki/JSON Date of extraction: 22 June, 2015

[35] XAMPP https://en.wikipedia.org/wiki/XAMPP Date of extraction: 22 June, 2015

[36] Google Maps API for Work https://www.google.com/work/mapsearth/products/maps api.html Date of extraction: 22 June, 2015 